\title{
Transport: A roadblock to climate change mitigation?
}

\section{Urban mobility solutions foster climate mitigation}

\section{By Felix Creutzig, ${ }^{1,2 *}$ Patrick Jochem, ${ }^{3}$ Oreane Y. Edelenbosch, ${ }^{4}$ Linus \\ Mattauch, ${ }^{1,2}$ Detlef P. van Vuuren, ${ }^{4,5}$ David McCollum, ${ }^{6}$ Jan Minx ${ }^{1,7}$}

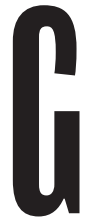

lobal emissions scenarios studies, such as those informing the Intergovernmental Panel on Climate Change (IPCC) 5th Assessment Report (AR5), highlight the importance of the transport sector for climate change mitigation along with the difficulties of achieving deep reductions therein (1) [supplementary materials (SM)]. Transport is responsible for about $23 \%$ of total energy-related $\mathrm{CO}_{2}$ emissions worldwide (2). The sector is growing more rapidly than most others, with emissions projected to double by 2050 . Global scenario studies, specifically those produced by integrated assessment models (IAMs), communicate aggregate mitigation potentials by sectors in IPCC reports. Yet recent evidence indicates that emissions may be reduced further than these global scenario studies suggest if policy-makers use the full suite of policies at their disposal.

If current trends continue, the global number of light-duty vehicles will roughly double by midcentury, driven by rising affluence especially in China, India, and South East Asia (3). Demand for freight transport (road, rail, shipping, and air) and passenger aviation is projected to surge as well.
In recent years, $\mathrm{CO}_{2}$ emissions from transport have stabilized in the European Union and the United States as fuel economy and emission standards were tightened. Municipalities worldwide have implemented local measures to reduce emissions of urban transport systems. However, these efforts have not been able to slow sectoral emission growth on the global level; there needs to be a broader suite of complementary, and enforced, policies in order to succeed.

The IPCC AR5 indicates that stabilization of $\mathrm{CO}_{2}$ emissions in the transport sector by 2050 at roughly 2010 levels would be consistent with the $2^{\circ} \mathrm{C}$ global mean temperature increase target [i.e., 430 to 480 parts per million (ppm) $\mathrm{CO}_{2}$-equivalent $\left(\mathrm{CO}_{2}\right.$-eq)] But this transport mitigation burden is conditional on emission reductions in other sectors. The 2050 target for the transport sector is relatively modest because, in these global emissions scenarios, the power sector often compensates for residual emissions in the transport sector by removing $\mathrm{CO}_{2}$ from the atmosphere via bioenergy and carbon capture and storage (SM). If non-transport reductions turn out to be more difficult to achieve, then transport would need to halve its emissions by midcentury.

CAN AMbitious $\mathrm{CO}_{2}$ REDUCTIONS BE ACHIEVED? Transport mitigation options can, in principle, lower emissions by reducing (i) overall transport demand growth (reducing distance traveled; shifting to more efficient modes), (ii) the amount of energy needed for propelling a vehicle over a given distance (increase fuel efficiency), or (iii) the carbon intensity of transport fuels $\left[\mathrm{gCO}_{2} / \mathrm{MJ}\right]$ (fuel shift). In global scenarios, options (ii) and (iii) form the main mitigation options (1). In contrast, many urban transport experts highlight the potential of option (i), such as compact urban development, bus rapid transit, bicycle highways, and telecommuting. As the last-mentioned options often lead to nonclimate benefits at the local level, they are increasingly becoming part of municipal agendas worldwide. But current-generation global IAMs lack necessary spatial and/or jurisdictional resolution to represent local, often idiosyncratic, solutions of this type. Whereas IAMs remain crucial for the big picture, transport-specific models with higher resolution in space and technological data complement IAMs and show that more ambitious mitigation appears plausible.

\section{“..transport could...nearly halve its $\mathrm{CO}_{2}$ emissions by midcentury...."}

We illustrate the main challenges using results of three representative scenario runs by the IAM IMAGE (see the figure, A to C) (SM) (4) in order to then contextualize the relevance of additional mitigation options. In the most ambitious case, total emissions in the transport sector will be 4.2 Gt $\mathrm{CO}_{2}$ in 2050, within the range of the 430 to $480 \mathrm{ppm} \mathrm{CO}_{2}$-eq scenarios. But which transport sector developments substantiate mitigation scenarios? We sketch key elements of the solution space, following the $\operatorname{IPCC}(1,2)$ and, drawing on other literature, point to two options in land passen-

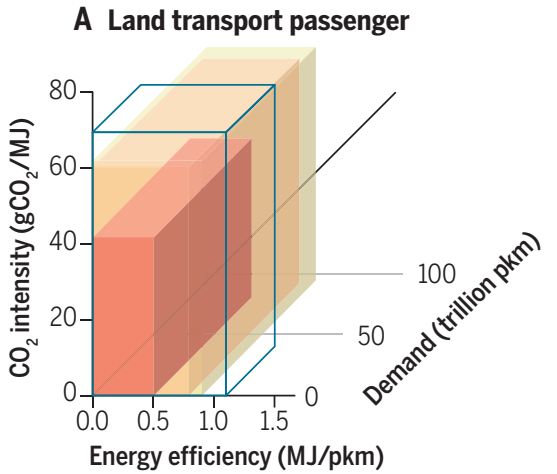

B Aviation passenger

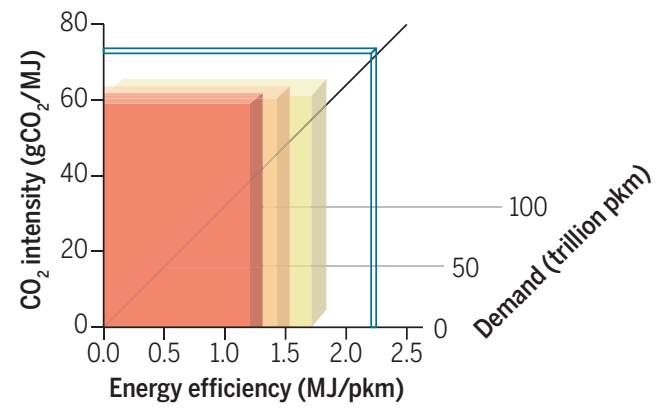

C Total freight

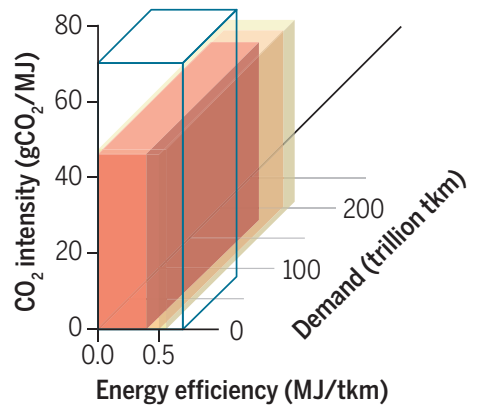

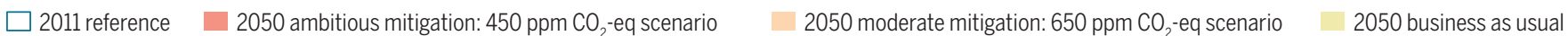

Modeled transport $\mathrm{CO}_{2}$ emissions, in 2011 and in 2050, based on data from 2005. (See SM). (A) Land passenger (passenger-kilometer, pkm); (B) aviation; and (C) freight transport (metric ton-kilometer, tkm), as modeled by the IAM IMAGE (14) (See SM). Emissions, calculated as the product of the three axes ( $\mathrm{CO}_{2}$ intensity, energy efficiency, and demand), can be visualized by the volume of the boxes. 
ger transport that complement the solution space: electric cars and urban transport demand management.

The scenarios show that passenger road transport continues to be responsible for the highest emissions share within the transport sector (part A); but aviation displays the highest growth in emissions (part B), consistent with historical trends of shifting to faster modes. Aviation requires considerable fuel per passenger-km traveled (part B), whereas maritime transport, a major component of freight demand, is highly fuel-efficient (part C).

Road transport could contribute a major mitigation share by (i) continuing to aggressively increase efficiency; (ii) shifting from fossil fuels to electric-drive vehicles;

\section{"Infrastructure investments and behavioral options can produce cost savings that are not typically included in global estimates of mitigation costs."}

and (iii) slowing demand growth, especially in urban settings. First, continuously improved technical standards in road transport in all major auto markets worldwide have resulted in efficiency gains for new light-duty vehicles of about 2 to $4 \%$ per year (5). Although this rate can be extrapolated for another decade, future efficiency gains are likely to become more costly without sacrificing vehicle size, safety, equipment, or comfort. But a shift in societal preferences toward smaller cars would allow for reduced incremental costs.

Second, deeply decarbonizing road transport would involve a large-scale shift from gasoline and diesel to biofuels, electricity, and/or hydrogen, either in dedicated battery-electric or fuel-cell vehicles or in mixed configurations, such as plugin hybrid-electric vehicles. Our scenario, similar to those assessed by AR5, indicates only partial decarbonization until 2050 (Fig. 1A), mostly because production of

${ }^{1}$ Mercator Research Institute on Global Commons and Climate Change (MCC), 10829 Berlin, Germany. ${ }^{2}$ Technical University Berlin, 10623 Berlin, Germany. ${ }^{3}$ Karlsruhe Institute of Technology (KIT), 76131 Karlsruhe, Germany. ${ }^{4}$ PBL Netherlands Environmental Assessment Agency, 3720AH Bilthoven, Netherlands. ${ }^{5}$ Copernicus Institute of Sustainable Development of Geosciences, Utrecht University, 3584CS Utrecht, Netherlands. ${ }^{6}$ International Institute for Applied Systems Analysis (IIASA), 2361 Laxenburg, Austria. ${ }^{7}$ Hertie School of Governance, 10117 Berlin, Germany. *Corresponding author.E mail: creutzig@mcc berlin.net advanced vehicle technologies and lowcarbon fuels with high-energy density are expected to remain costly for several decades (relative to gasoline and diesel used in efficient conventional vehicles). There is no agreement on which of the three alternative energy carriers will replace for fossil liquid fuels in the long term, but it appears likely that one or several of these will come to dominate in the second half of this century if deep cuts in emissions are to be achieved (6). Battery-electric mobility, for instance, might take off faster than expected owing to substantial declines in battery prices (7), which would make battery-electric travel less expensive than conventional fossil fuel based mobility [(8) see also SM]. Hence, battery-electric cars are likely to reduce emissions further until 2050 [even though indirect emissions from electricity generation are not negligible (9)], on top of the emission reduction shown in IMAGE.

Third, infrastructure development, landuse policies and behavioral interventions can catalyze further emission reductions; these, however, are hard to assess quantitatively in current-generation global IAMs that lack the fine-scale resolution of local infrastructure and behavioral issues (10). In general, those strategies are not modeled explicitly. Options include shifting to modes with low carbon intensities, parking management and congestion charges, smart growth policies, and behavioral measures. Such options also carry potentially large social benefits, e.g., reduced noise, air pollution; traffic congestion; and risk of obesity-related diseases, depression, and dementia, which often create strong incentives for local action. In sum, the combined mitigation potential in urban transport via spatial planning, transport pricing, and behavioral options amounts to 20 to $50 \%$ between 2010 and 2050, compared with baseline (11) (fig. S1).

Infrastructure investments and behavioral options can produce cost savings that are not typically included in global estimates of mitigation costs. Although lowcarbon infrastructure options may include expensive up-front construction (e.g., highspeed rail tracks), such investments could lead to enormous savings from building and maintaining fewer roads and parking spaces over coming decades. One study puts these infrastructure investment cost savings for low-carbon transport at around $\$ 20$ trillion by 2050 globally (12). Rededicating existing urban infrastructure to non-motorized transport (e.g., pedestrian zones and bicycle lanes) can be achieved at little cost. Behavioral interventions have mostly zero or low monetary costs (SM), but unlocking their considerable mitigation potential requires policies that explicitly take nonstandard preferences, beliefs, and decision-making processes into account, as well as normative considerations of policy-makers (13).

If both urban transport mitigation options and increasingly cost-effective batteryelectric cars are fully utilized, there are reasons to believe global transport could be on track to nearly halve its $\mathrm{CO}_{2}$ emissions by midcentury, which would bring the sector in line with the $2^{\circ} \mathrm{C}$ target (SM). Higher fuel taxes would foster long-term development toward compact urban form and low-carbon urban transport (14) and, at the same time, incentivize faster market penetration of battery-electric vehicles (7). In fact, avoiding rebound effects associated with the substantially greater efficiency of electric vehicles necessitates high prices on fossil fuels. So far, however, we see little global appetite among policy-makers for seriously discussing thorny transport issues in public debates and international climate negotiations. Unless this changes swiftly, transport may remain a roadblock to the world's efforts to mitigate climate change.

\section{REFERENCES AND NOTES}

1. O. Edenhofer et al., in Climate Change 2014: Mitigation of Climate Change. Contribution of Working Group III to the Fifth Assessment Report of the Intergovernmental Panel on Climate Change, O. Edenhofer et al., Eds. (Cambridge Univ. Press, New York, 2014), pp. 33108

2. R. Sims et al., in Climate Change 2014: Mitigation of Climate Change. Contribution of Working Group III to the Fifth Assessment Report of the Intergovernmental Panel on Climate Change, 0. Edenhofer et al., Eds. (Cambridge Univ. Press, New York, 2014), pp. 599670.

3. D. Sperling, D. Gordon, Two Billion Cars (Oxford Univ. Press, New York, 2009).

4. B. Girod, D. P. van Vuuren, S. Deetman, Energy Policy 45 , 152 (2012).

5. S. L. Winkler, T.J. Wallington, H. Maas, H. Hass, Environ. Sci. Technol. 48,6453 (2014)

6. R. Pietzcker et al., Energy 64, 95 (2014).

7. B. Nykvist, M. Nilsson, Nat. Clim. Change 5,329 (2015).

8. National Research Council, Transitions to Alternative Fuels and Vehicles (National Academies Press, Washington, DC, 2013).

9. P. Jochem, S. Babrowski, W. Fichtner, Transp. Res. A: Policy Pract. 78,68(2015)

10. T. Schwanen, D. Banister, J. Anable, Transp. Res. A Policy Pract. 45, 993 (2011)

11. F. Creutzig, Transp. Rev. 10.1080/01441647.2015.1079277 (2015)

12. J. Dulac, "Global land transport infrastructure require ments" (International Energy Agency, Paris, 2013).

13. L. Mattauch, M. Ridgway, F. Creutzig, Transp. Res. PartD Transp. Environ. 10.1016/j.trd.2015.08.006 (2015)

14. F. Creutzig, Urban Clim. 10,63 (2014).

\section{ACKNOWLEDGMENTS}

We thank B. Girod and J. Römer for support in modeling and R. Pietzcker, W. Rothengatter, and Y. Hayashi for helpful discus sions. We acknowledge funding by EU Framework Programme 7 (FP 7) 20072013 no.308329 (ADVANCE). 


\section{Repository KITopen}

Dies ist ein Postprint/begutachtetes Manuskript.

Empfohlene Zitierung:

Creutzig, F.; Jochem, P.; Edelenbosch, O. Y.; Mattauch, L.; Vuuren, D. P. van; McCollum, D.; Minx, J.

Transport: A roadblock to climate change mitigation?.

2015. Science, 350.

doi:10.554/IR/1000055150

Zitierung der Originalveröffentlichung:

Creutzig, F.; Jochem, P.; Edelenbosch, O. Y.; Mattauch, L.; Vuuren, D. P. van; McCollum, D.; Minx, J.

Transport: A roadblock to climate change mitigation?.

2015. Science, 350 (6263), 911-912.

doi:10.1126/science.aac8033 